\title{
TECNOLOGIAS DE INFORMAÇÃO E COMUNICAÇÃO NA EDUCAÇÃO: um desafio na prática docente ${ }^{*}$
}

\author{
INFORMATION AND COMMUNICATION TECHNOLOGIES IN EDUCATION: \\ a challenge in teaching practice
}

\author{
Nara Caetano Rodrigues \\ Universidade Federal de Santa Catarina-UFSC
}

\begin{abstract}
Resumo
Neste artigo, pretende-se discutir o uso das tecnologias de informação e de comunicação na educação e os saberes necessários ao professor para atuar frente a essa demanda. Em um primeiro momento, será feita uma reflexão sobre a inserção de recursos tecnológicos nas escolas com fins educativos e a reação no ambiente escolar, bem como sobre sua influência na mudança nas práticas do professor. Posteriormente, serão analisados os dados obtidos por meio da aplicação de um instrumento de geração de dados, com o objetivo de investigar como os/as professores/as de uma escola pública federal de ensino fundamental e médio, localizada em Florianópolis/SC, estão se posicionando frente ao desafio da utilização das tecnologias na sua prática educacional.
\end{abstract}

Palavras chaves: Tecnologias de informação e de comunicação. Prática docente. Educação básica.

\begin{abstract}
This article discusses the use of information and communication technologies in education and the knowledge teachers need in order to face these requirements. Initially, a reflection will be made on the insertion in schools of technological resources with educative purposes, and also on the reaction within the school environment, as well as on the influence of those resources on teaching practices. Afterwards, the data obtained by means of the application of a research instrument will be analyzed, aiming to investigate how the teachers of a federal public school located in Florianópolis/SC react to the challenge of using new technologies in their teaching practice.
\end{abstract}

Keywords: Information and communication technologies. Teaching practice. Basic education.

\section{INTRODUÇÃo}

Os profissionais da educação defrontam-se hoje com exigências de ordens diversas no sentido de incorporarem à sua prática em sala de aula as tecnologias de informação e comunicação (TICs) ${ }^{1}$. Documentos oficiais como os Parâmetros Curriculares Nacionais

\footnotetext{
* Este artigo foi produzido, em 2006, sob orientação da Profa ${ }^{\text {a }}{ }^{\mathrm{a}}$ Nilcéa Lemos Pelandré, como parte do processo de qualificação ao doutorado em Linguística Aplicada no Programa de Pós-Graduação em Linguística da UFSC e aprovado pela banca examinadora em fevereiro de 2007.

${ }^{1}$ A expressão tecnologias da comunicação e da informação está sendo usada aqui com referência apenas a uma parte dos recursos tecnológicos que permitem o trânsito de informações: "Os meios eletrônicos que
} 
(PCNs e PCNEM) recomendam o uso dessas tecnologias: "É indiscutível a necessidade crescente do uso de computadores pelos alunos como instrumento de aprendizagem escolar, para que possam estar atualizados em relação às novas tecnologias da informação e se instrumentalizarem para as demandas sociais presentes e futuras." (BRASIL, 1998, p. 96) "As tecnologias da comunicação e da informação e seu estudo devem permear o currículo e suas disciplinas." (BRASIL, 1999, p. 134) Esses documentos apresentam-se como diretrizes norteadoras do ensino e exercem certa influência na atuação docente, mas é da relação cotidiana com os alunos que vem a demanda - às vezes, impiedosa e até mesmo pouco criteriosa - pela diversificação de recursos e aproveitamento das possibilidades desses nas atividades educacionais. Muitos dos alunos da escola em que aconteceu a pesquisa são representantes de uma geração que incorporou tecnologias, como o computador e o telefone celular, à sua rotina, seja no lazer, na comunicação pessoal ou nas tarefas da escola ${ }^{2}$. Segundo Trahtemberg (2000, p. 6), "El profesor deberá acompañar al alumno em el proceso de organizar la realidad y la información que lo rodea, para que pueda hacer um uso productivo de ellas y construir su próprio conocimiento. ?Pueden los profesores lidiar com estos retos?”

O universo das tecnologias de informação e comunicação apresenta-se - ou impõe-se -, nesse momento, como um imenso oceano, ainda inexplorado, desconhecido para muitos educadores; fascinante e cheio de possibilidades para outros. Ponte (2000, p. 2) destaca que o processo de apropriação das TICs, além de ser necessariamente longo, envolve duas facetas as quais não se pode confundir: a tecnológica e a pedagógica. Assim, não é de admirar as atitudes dos professores em relação às tecnologias de informação e comunicação:

\begin{abstract}
Alguns olham-nas com desconfiança, procurando adiar o máximo possível o momento do encontro indesejado. Outros usam-nas na sua vida diária, mas não sabem muito bem como as integrar na sua prática profissional. Outros, ainda, procuram usá-las nas suas aulas sem, contudo, alterar as suas práticas. Uma minoria entusiasta desbrava caminho, explorando incessantemente novos produtos e idéias, porém defronta-se com muitas dificuldades como também perplexidades.
\end{abstract}

Para problematizar tema tão polêmico, inicialmente se faz necessário conhecer um pouco a história da chegada dessas tecnologias às escolas e as mudanças provocadas nos saberes exigidos do professor. Posteriormente, a partir da análise dos dados coletados junto a professores/as de uma escola pública federal de educação básica, localizada em Florianópolis/SC, procuraremos situar a questão nesse contexto particular (ensino fundamental e médio) a fim de ter um panorama dos recursos tecnológicos mais usados

incluem as tecnologias mais tradicionais, como rádio, televisão, gravação de áudio e vídeo, além de sistemas multimídias, redes telemáticas, robótica e outros". Apesar de os PCNs trazerem um conceito mais amplo das TICs, compreendendo "[...] os diferentes meios de comunicação (jornalismo impresso, rádio e televisão), os livros, os computadores etc" (BRASIL, 1998, p. 135), o conceito mais restrito foi adotado com o objetivo de fazer um recorte na presente abordagem.

${ }^{2}$ As questões relacionadas à exclusão digital, apesar de serem extremamente pertinentes, não serão discutidas aqui por não constituírem o foco desse artigo. Sabemos, no entanto, que a realidade de uma parcela significativa do público que freqüenta a escola em que se deu a pesquisa não é a realidade dos alunos da maioria das escolas públicas brasileiras. 
pelos/as professores/as, verificar os fatores que impedem ou dificultam o uso das tecnologias na prática docente desses profissionais e conhecer a opinião do grupo participante da pesquisa sobre as características necessárias ao professor/a para a utilização das tecnologias com fins educacionais.

\section{2 "NAVEGAR É PRECISO ..."}

Muito se tem discutido, principalmente nas últimas duas décadas, a respeito do uso das tecnologias de informação e comunicação nas escolas, entretanto a discussão envolvendo educação e tecnologia não é tão recente e não teve início com a expansão/"popularização" do acesso aos computadores pessoais. Essa acepção torna-se mais plausível se tomado o conceito de tecnologia ${ }^{3}$ no sentido adotado por Carneiro (2002, p. 49), que usa o termo tecnologias referindo-se aos recursos já amplamente utilizados na escola, como lousa, giz, livro didático, lápis, inclusive a linguagem e a exposição oral e, ainda, a própria instituição escola. Para a autora, tais recursos "[...] fazem parte da tecnologia da educação, juntamente com a TV, o retroprojetor, o vídeo e o computador."

Por outro lado, é preciso reconhecer que a tecnologia, em muitos momentos, foi responsável pelo surgimento de novas formas de acesso ao conhecimento. Segundo Niskier (1993, p. 40), a radiodifusão com finalidades educativas, nasceu no Brasil em 1923, quando foi fundada a Rádio Sociedade do Rio de Janeiro, que transmitia programas de literatura, radiotelegrafia e telefonia, de línguas, de literatura infantil entre outros. Mais tarde, surgiu a Teleducação ${ }^{4}$, cuja experiência mais significativa - o Telecurso $2^{\circ}$ grau - teve início em 1977, numa parceria entre a Fundação Roberto Marinho e a Fundação Padre Anchieta (NISKIER, 1993, p. 73).

Já o uso da informática na educação passou a ser objeto de estudo ainda no final da década de 1970, por meio do projeto Educação com Computador (EDUCOM) - o qual se constituiu como "[...] a primeira ação oficial e concreta para levar os computadores até as escolas públicas." (TAJRA, 1998, p. 14) A Unicamp foi uma das universidades que se constituiu como centro-piloto de estudo. Em 1979, deu início à pesquisa da adaptação da linguagem logo original para o português, com o objetivo de criar versões nacionais para os comandos. Niskier (1993, p. 102) destaca que, nesse projeto, "[...] o aluno, em vez de uma atitude passiva diante da máquina, interage diretamente com ela, transformando um processo de aprendizagem completamente diferente do usual: o aluno está constantemente ensinando o computador." É preciso ponderar, entretanto, que a interação possível nas adaptações da linguagem logo, realizadas no final da década de 1970, era um diferencial se comparada à cultura monológica característica das outras tecnologias utilizadas na época: gravador, videocassete, televisão...

\footnotetext{
${ }^{3}$ Para uma reflexão mais aprofundada das diversas acepções do termo "tecnologia", ver Vieira Pinto (2005, p. 219-355). O autor faz uma distinção entre quatro significados principais: a) estudo da técnica; b) tecnologia como equivalente de técnica (know-how); c) "conjunto de todas as técnicas de que dispõe uma determinada sociedade”; d) "ideologização da técnica", sendo este último significado - tecnologia como instrumento de dominação - o que recebe maior atenção desse mesmo autor.

${ }^{4} \mathrm{O}$ termo teleducação passa a ser adotado, em 1969, na Conferência Internacional dos países membros da OEA, e abrange atividades educativas por rádio, televisão e outros meios audiovisuais a distância (NISKIER, 1993, p. 42).
} 
Com o intuito de avaliar a contribuição do computador no processo pedagógico, segundo Carneiro (2002, p. 49), "[...] no início da década de 80, começa a desenvolverse a Política de Informática Educativa (PIE), caracterizada por atividades de pesquisa e seminários de discussão em pequena escala."

A autora aponta o Programa Nacional de Informática na Educação ${ }^{5}$ (PROINFO) e os Parâmetros Curriculares Nacionais como manifestações da preocupação do governo brasileiro com o uso das tecnologias na educação. Carneiro (2002, p. 50-51) destaca, dentre as razões oficiais para a implantação dos computadores nas escolas, a aproximação da escola dos avanços da sociedade no que se refere ao armazenamento, à transformação, à produção e à transmissão de informações, favorecendo a diminuição da lacuna existente entre o mundo da escola e a vida do aluno - o que diminuiria também "[...] as diferenças de oportunidade entre a escola pública e a particular, cada vez mais informatizada." Por outro lado, ela ressalta que "[...] pouco se discute quais os modos de informatização que estão sendo trabalhados e com que finalidade."

Há pouco mais de uma década, Niskier (1993, p. 100) apontava como principal motivo de resistência por parte dos professores a possibilidade de eles serem substituídos pelos recursos tecnológicos: "O uso do computador na educação está em plena ascensão em diversos países. O receio inicial de que a máquina poderia vir a substituir o professor aos poucos está sendo desmistificado".

Uma década depois, Carneiro (2002, p. 23) também discute a história recente da criação e utilização dos computadores e a sua imagem associada aos objetivos bélicos e à automação industrial, com o trabalho humano sendo substituído por enormes máquinas, gerando desemprego.

Há reflexões que apontam desdobramentos mais complexos para essa questão quando associada à educação. Blikstein e Zuffo (2003, p.23) comparam as novas tecnologias da comunicação e da informação com os cantos das sereias as quais seduzem e encantam, para depois devorar sem piedade suas presas. As primeiras vítimas das "encantantes melodias das novas tecnologias" teriam sido os profissionais da informática, do comércio eletrônico e os web-jornalistas; o próximo alvo das sereias seriam os educadores.

Os autores apontam algumas bandeiras da nova educação, citando o estímulo à criatividade, o acesso à educação de qualidade, a pedagogia de projetos, a educação por toda a vida e centrada no aluno; entretanto, para Blikstein e Zuffo (2003, p. 25), “[...] as respostas concretas a esses desafios ainda são raras e difusas.” Na sua opinião, essas tecnologias são vistas como possibilidade de solução para todos os problemas da educação.

Eles ressaltam ainda que as vantagens propagandeadas pelos defensores do ensino com o uso das tecnologias, como a atualização profissional via ensino a distância (EaD), por exemplo, exigem uma análise cuidadosa. Como dizem os autores, citando o pesquisador

\footnotetext{
${ }^{5}$ O Programa Nacional de Informática na Educação foi criado em 1997 e é uma iniciativa do Ministério da Educação; tem como foco de suas ações a capacitação de multiplicadores e de escolas para o uso da telemática em sala de aula e é desenvolvido em parceria com os governos estaduais e alguns municipais (ROJO; BARBOSA; COLLIN, 2005, p. 156).
} 
francês Eric Barchechat, “[...] assistimos a um processo de transferência da responsabilidade pela atualização profissional (e da culpa da eventual estagnação pessoal) da empresa para o empregado, assim como boa parte dos seus custos." (BLIKSTEIN e ZUFFO, 2003, p. 30)

Por mais que a lógica do consumo esteja se aproximando cada vez mais da educação, ainda assim, comparar a lógica das empresas à lógica das escolas parece uma antecipação de um futuro catastrófico, maquiavélico, sem saída para quem acredita que a educação não é um negócio.

Talvez as políticas públicas para o ensino superior estejam colocando as universidades no mesmo patamar das empresas, mas isso não teve início com as tecnologias de informação e de comunicação. Independentemente dessa "novidade”, "a transformação do conhecimento científico e tecnológico em um produto comercializável” é um processo evidente principalmente em algumas áreas das universidades há muito tempo.

Blikstein e Zuffo (2003, p. 33, grifos do autor) “carregam nas tintas” ao apresentar o quadro da situação dos professores e alunos nas universidades, citando Nobre, que "[...] alerta para a tendência de proletarização da atividade educacional, aumento da velocidade, padronização do trabalho, maior disciplina e supervisão gerencial, menor autonomia e a contaminação da lógica de redução de custos e aumento da lucratividade."

Não obstante os senões apresentados, os autores sinalizam aspectos positivos da internet, como a anonimidade, a eliminação de distâncias entre as pessoas, a descentralização de conhecimento, entre outros. Destacam, por outro lado, o valor da internet como matéria-prima de construção na educação em detrimento de seu uso como mídia de transmissão de informações (BLIKSTEIN; ZUFFO, 2003, p. 36).

Essa posição um pouco mais receptiva se aproxima de algumas opiniões de Kenski, pedagoga e doutora em educação, Coordenadora do Grupo de Estudos e Pesquisas sobre Memória, Ensino e Novas Tecnologias (MENT). Ela não ignora, por exemplo, que há um comércio de programas com baixa qualidade didática, elaborados por equipes de técnicos que não entendem de educação; esses materiais são adquiridos acriticamente por diretores e professores. Mas a autora encara de um modo mais otimista as possibilidades de entrar nesse "embate":

Uma das soluções para esse impasse está na possibilidade de educadores também participarem das equipes produtoras dessas novas tecnologias educativas. Para isso é preciso que os cursos de formação de professores se preocupem em lhes garantir essas novas competências. Que ao lado do saber científico e do saber pedagógico, sejam oferecidas ao professor as condições para ser agente, produtor, operador e crítico dessas novas educações mediadas pelas tecnologias eletrônicas de comunicação e informação (KENSKI, 2003, p. 49-50).

A autora também reconhece que, na maioria das escolas brasileiras, as tecnologias digitais de comunicação e de informação "[...] são impostas, como estratégia comercial e política, sem a adequada reestruturação administrativa, sem reflexão e sem a devida preparação do quadro de profissionais que ali atuam." (KENSKI, 2003, p.70) Ela 
destaca que é preciso, além da infraestrutura tecnológica, que o propósito da escola seja revisto, que sejam discutidas questões estruturais como: "Que tipo de aluno vai ter acesso a esses meios? Com que finalidade? Ensinar computação ou ensinar com o auxílio do computador? Que alterações curriculares acarretarão essas transformações? Que formação será necessária aos professores que vão atuar com os novos meios?" (KENSKI, 2003, p. 75).

Ponte (2000, p. 6-7) problematiza a integração das TICs na escola e defende que, para além dos questionamentos sobre a relação entre essas tecnologias e (i) os objetivos da escola, (ii) as formas de aprendizagem, (iii) os novos modos de trabalho na escola, é preciso ir mais longe e questionar a escola com outro tipo de pergunta:

(iv) de que modo as TIC alteram (ou podem alterar) a natureza dos objetivos educacionais visados pela escola? (v) de que modo alteram as relações entre os alunos e o saber? (vi) de que modo alteram as relações entre alunos e professores? (vii) de que modo alteram o modo como os professores vivem sua profissão? (viii) a emergência da sociedade de informação requer ou não uma nova pedagogia?

Para Maggio (1997, p. 17), é necessário que se faça uma reconceitualização do campo da Tecnologia Educacional, pois não há uma regularidade nas discussões acerca do campo. A autora acrescenta que ainda falta "[...] uma discussão substantiva a respeito do objeto, das condições de produção de conhecimento nesta linha disciplinar e, particularmente, seu status epistemológico.”

Com relação à formação adequada dos professores, Kenski ressalta que os programas aligeirados de preparação docente para o uso das TICs são falhos, instruem sobre o uso das máquinas sem outro tipo de apoio para criar novas possibilidades pedagógicas, o que gera insatisfação tanto para professores como para alunos. Ela cita estudos que apontam para um período de capacitação que compreende até quatro ou cinco anos para que o professor possa desenvolver novas habilidades de ensino, utilizando a tecnologia como ferramenta. Na sua opinião, não é suficiente os professores terem o conhecimento instrucional de como operar novos equipamentos para utilizarem esse meio como auxiliar para transformar a escola. Dada a complexidade do meio tecnológico, as atividades de aproximação entre docentes e tecnologia devem ocorrer, de preferência, nas licenciaturas e nos cursos de pedagogia (KENSKI, 2003).

Masetto (2004, p. 133) problematiza o uso da tecnologia como mediação pedagógica no processo de aprendizagem, começando pelo fato de que, por muito tempo, acreditou-se que educar significava transmissão de conhecimento organizado e sistematizado de diversas áreas e exigência de memorização e reprodução de informações (nas provas).

Decorrente dessa visão, o autor aponta o fato de que, nos cursos de formação de professores, "[...] percebe-se por parte dos alunos a valorização do domínio de conteúdo nas áreas específicas em detrimento das disciplinas pedagógicas." (MASETTO, 2004, p. 134) Vale acrescentar que esse desprestígio às disciplinas pedagógicas é reforçado quando não incitado - por muitos professores nos cursos de licenciatura. De acordo com Masetto (2004, p. 135), 
Nos próprios cursos de ensino superior, o uso de tecnologia adequada ao processo de aprendizagem e variada para motivar o aluno não é tão comum, o que faz com que os novos professores do ensino fundamental e médio, ao ministrarem suas aulas, praticamente copiem o modo de fazê-lo e o próprio comportamento de alguns de seus professores de faculdade, dando aula expositiva e, às vezes, sugerindo algum trabalho em grupo com pouca ou nenhuma orientação.

Não obstante esses problemas com a tecnologia, Masetto (2004) menciona fatos que realimentam a discussão sobre a mediação pedagógica e o uso da tecnologia, começando pelo surgimento da informática e da telemática que proporcionaram inúmeras possibilidades de acesso e construção ao/do conhecimento, utilizando uma enorme diversidade de recursos multimídia e as novas formas de interação a distância via internet.

O autor menciona também a recente abertura no ensino superior para a formação e desenvolvimento das competências pedagógicas dos professores universitários. Ao buscar a formação pedagógica de que necessitam, professores de diversas áreas, mestrandos e doutorandos de diversos programas de pós-graduação "[...] ao mesmo tempo em que buscam novas metodologias de aula, procuram também a discussão de seus papéis como professores e da maneira como se relacionam com seus alunos em aula, como motivá-los etc." (MASETTO, 2004, p. 138).

Tardif (2002) caracteriza os saberes profissionais dos professores como temporais, ou seja, são adquiridos através do tempo. Nesse sentido, a história de vida escolar produz uma bagagem de conhecimentos, adquirida ao longo de aproximadamente dezesseis anos de imersão em seu espaço de trabalho antes de começar a trabalhar formalmente como docentes. Para o autor, "Os alunos passam pelos cursos de formação de professores sem modificar suas crenças anteriores sobre o ensino. E, quando começam a trabalhar como professores, são principalmente essas crenças que eles reativam para solucionar seus problemas.” (TARDIF, 2002, p. 261)

Lévy (2005, p. 171), ao comentar o novo papel do professor, traz a noção da aprendizagem cooperativa, citando os novos campi virtuais, nos quais os "[...] professores aprendem ao mesmo tempo que os estudantes e atualizam continuamente tanto seus saberes 'disciplinares' como suas competências pedagógicas." Respondendo ao próprio questionamento sobre como manter as práticas pedagógicas atualizadas frente a esses novos desafios, o filósofo francês diz que

Não se trata aqui de utilizar as tecnologias a qualquer custo, mas sim de acompanhar consciente e deliberadamente uma mudança de civilização que questiona profundamente as formas institucionais, as mentalidades e a cultura dos sistemas educacionais tradicionais e, sobretudo, os papéis de professor e de aluno (LÉVY, 2005, p. 172, grifos do autor).

Com a mudança no papel do professor, de especialista que possui e transmite o conhecimento para o de mediador, incentivador e orientador no processo de aprendizagem, surgem novas exigências para o profissional que vai atuar como mediador pedagógico (MASETTO, 2004). 
Inspirada na expressão cunhada por Lévy (1993) - "arquitetos cognitivos" -, Ramal (2002, p. 191) delineia o perfil ${ }^{6}$ do profissional para atuar no campo educacional, frente à demanda pela incorporação das tecnologias e das mídias:

O arquiteto cognitivo: (a) é um profissional; (b) capaz de traçar estratégias e mapas de navegação que permitam ao aluno empreender, de forma autônoma e integrada, os próprios caminhos da construção do (hiper) conhecimento em rede; (c) assumindo, para isso, uma postura consciente de reflexão-na-ação; e (d) fazendo uso crítico das tecnologias como novos ambientes de aprendizagem.

Tardif (1991, p. 221) refere-se aos conhecimentos, competências e habilidades constitutivos da prática dos professores como "saberes docentes”. Para esse autor, “[...] o(a) professor(a) padrão é alguém que deve conhecer sua matéria, sua disciplina e seu programa, que deve possuir certos conhecimentos das ciências da educação e da pedagogia, sem deixar de desenvolver um saber prático fundado em sua experiência cotidiana com os alunos.”

Segundo Tardif, a transmissão dos conhecimentos constituídos é apenas uma das funções da prática docente que é formada por um conjunto de saberes mobilizados pelos professores diariamente. Assim, o saber docente é um saber plural composto de saberes oriundos de diferentes fontes: saberes da formação profissional (ciências da educação e ideologia pedagógica, cujos responsáveis pela transmissão são as faculdades de educação e os programas de formação de professores); saberes das disciplinas (como matemática, história, literatura - emergentes da tradição cultural e transmitidos nos diversos programas e departamentos universitários); saberes curriculares (discursos, objetivos, conteúdos e métodos, selecionados dos saberes sociais pela instituição escolar); saberes da experiência (saber fazer e saber ser, desenvolvidos pelos próprios professores na sua prática cotidiana (cf. TARDIF, 1991).

A seguir, serão analisadas as respostas de um grupo de professores/as de uma escola pública de Florianópolis/SC sobre o uso das TICs na educação e as características que o grupo considera necessárias ao profissional para incorporar tal uso em sua prática.

\section{COM A PALAVRA OS/AS PROFESSORES/AS...}

A fim de obter a opinião de profissionais da educação que estão em sala de aula, foi aplicado um instrumento de geração de dados constituído por dez perguntas fechadas e abertas, divididas em duas partes:

$1^{a}$ Parte - Identificação - Composta por cinco perguntas relacionadas a sexo, área de atuação, titulação e ano de formação, situação funcional e ano de ingresso na instituição.

\footnotetext{
${ }^{6}$ Embora faça referência ao trabalho de Tardif sobre a profissionalização do trabalho docente, Ramal desenvolve seu estudo na perspectiva de que há um perfil necessário ao profissional que vai fazer uso das tecnologias da informação e da comunicação na sua prática pedagógica.
} 
$2^{\text {a }}$ Parte - Tecnologias da comunicação e da informação - Composta por cinco perguntas temáticas e um espaço para comentário livre sobre o assunto da pesquisa. As perguntas versam sobre: recursos tecnológicos disponíveis na escola; recursos tecnológicos utilizados em sala de aula; ambientes virtuais utilizados pelos/as professores/as para atividades pessoais; ambientes virtuais utilizados pelos/as professores/as para atividades educacionais; fatores que impedem ou dificultam o uso das tecnologias na prática docente desses profissionais; características necessárias ao professor/a para a utilização das tecnologias com fins educacionais; aspectos positivos da utilização das tecnologias na educação; aspectos negativos da utilização das tecnologias na educação; material educativo multimídia utilizado pelos/as professores/as; sites consultados ou indicados para os alunos.

Com o objetivo de centrar o foco da análise no posicionamento dos/as professores/as frente a esse novo desafio, foi necessário fazer um recorte nas informações fornecidas. Assim, neste artigo, serão abordados apenas os tópicos referentes ao perfil dos/as professores/as, ao uso das tecnologias e às características necessárias ao profissional da educação nesse contexto.

O instrumento de pesquisa elaborado pela pesquisadora encontra-se em anexo, bem como as respostas das perguntas focalizadas aqui. Embora neste momento seja discutida apenas parte das informações, os dados foram documentados e poderão ser analisados em trabalhos futuros.

\subsection{Perfil do grupo participante da pesquisa}

A escola pertence à rede pública federal, possui cerca de 900 alunos e 110 professores, dentre os quais 32 participaram da pesquisa, o que corresponde a $29 \%$ do total. Com base nas respostas fornecidas na primeira parte do instrumento de pesquisa, é possível traçar um perfil do grupo participante da pesquisa: é composto por 9 professores e 23 professoras que atuam no ensino fundamental e no ensino médio e possuem a seguinte titulação máxima: 4 têm graduação (12,5\%); 3 têm especialização (9,37\%); 20 têm mestrado (62,5\%) e 5 têm doutorado (15,62\%).

Quanto à situação funcional, 26 são efetivos (81,25\%) e 6 são substitutos (18,75\%). A data de ingresso na instituição vai de 1974 a 2005, e o ano de conclusão da graduação vai de 1968 a 2005; ou seja, há profissionais com mais de trinta anos de experiência e há recém-formados que estão em sua primeira experiência profissional.

As disciplinas ministradas pelos/as professores/as foram relacionadas em quatro áreas: as três primeiras seguem a estruturação definida nos PCNEM (BRASIL, 1999): $1^{\text {a }}$ ) área de linguagens, códigos e suas tecnologias: Educação Física, Língua Portuguesa, Inglês, Espanhol, Arte - totalizando 15 professores nessa área; $2^{a}$ ) área de ciências humanas e suas tecnologias: História, Geografia, Sociologia - totalizando 7 professores nessa área; $3^{\mathrm{a}}$ ) área de ciências da natureza, matemática e suas tecnologias: Ciências Biológicas e Física - totalizando 5 professores nessa área. O quarto grupo foi acrescentado para contemplar dois pedagogos que atuam nas Séries Iniciais e os especialistas que participaram da pesquisa: um orientador educacional e dois supervisores escolares. $\mathrm{O}$ 
que se percebe é que o grupo que se dispôs a participar da pesquisa é bastante heterogêneo quanto à experiência profissional. Entretanto, quanto à titulação e à situação funcional há, respectivamente, um predomínio de mestres e professores/as efetivos/as.

Quanto à disciplina na qual atuam, houve uma participação maior de professores de Geografia e Educação Física (05 de cada) e professores de Língua Portuguesa e Ciências Biológicas (04 de cada disciplina). Não houve participação de professores que atuam nas seguintes disciplinas: Alemão, Filosofia, Francês e Química.

\subsection{Recursos tecnológicos utilizados pelos/as professores/as}

Na segunda parte do instrumento de pesquisa, a partir das respostas dadas, percebe-se que os recursos tecnológicos mais utilizados, nas atividades com os alunos, por aproximadamente 70 a $80 \%$ dos/as professores/as, são o videocassete, o DVD, o data show, o aparelho para CD e o televisor. O computador aparece em $6^{\circ}$ (sexto) lugar, ou seja, 53,12\% dos profissionais disseram utilizá-lo na sua prática docente. Já os recursos como gravador, filmadora e rádio foram citados por $25 \%$ ou menos dos/as professores/as.

Vale destacar que 96,87\% dos/as professores/as informaram ter conhecimento de que a escola dispõe de computadores em rede, entretanto pouco mais da metade diz fazer uso de tal recurso em suas aulas - o mesmo percentual de profissionais que diz utilizar ambientes virtuais para desenvolver atividades com os alunos. Esse dado contrasta com os $96,87 \%$ que dizem utilizar ambientes virtuais para atividades como comunicação pessoal, atualização, formação e lazer. O uso do e-mail é indicado por 93,75\% dos professores/as e $90,62 \%$ dizem utilizar a rede para atividades pessoais, entretanto apenas 43,75\% dos/as professores/as informaram utilizar esses ambientes virtuais para desenvolverem atividades com os alunos.

Dentre os/as 13 professores/as (40,62\% do total) que disseram não utilizar nenhum ambiente virtual para atividades com alunos, o motivo recorrente em cinco das justificativas foi a falta de infraestrutura na escola, como se pode ver nos seguintes depoimentos $^{7}$ :

P2 - O Colégio não está adequadamente equipado.

P4 - Na escola não há condições.

P11 - Não dispomos de laboratório multimedia, então o único modo possível é trabalhar via e-mail com os alunos que tenham internet em casa.

P14 - [Não utilizo] pois falta o ambiente no colégio (não temos esse recurso disponível para utilizá-lo durante as aulas).

P18 - A carência de infra-estrutura, para este fim, na escola não me assegura sobre a qualidade das pesquisas que serão feitas sem orientação prévia adequada.

\footnotetext{
${ }^{7}$ Tanto aqui quanto na sequência deste artigo, as respostas foram transcritas respeitando-se o registro feito pelos/as professores/as.
} 
Esse dado se confirma na indicação dos fatores que impedem ou dificultam o uso das tecnologias na prática docente dos participantes da pesquisa; o fator assinalado por 20 professores/as (62,5\% do total) faz uma referência genérica à falta de equipamento adequado no local de trabalho. Para reforçar tal aspecto, cinco dos/as sete professores/as que acrescentaram outros fatores à relação fornecida também fizeram referência a problemas de infraestrutura, conforme se pode observar nas respostas:

P1 - O colégio dispõe de poucos equipamentos para serem utilizados por alunos.

P17 - Não existe sala de informática para os alunos.

P22 - A escola não dispõe de equipamentos para trabalharmos com os alunos (sala de micro).

P27 - Não há [...] um lab. de informática c/ PCs em rede que possibilite um trabalho c/ 25 alunos simultaneamente.

P30 - Pouco tempo disponível para uso do auditório (data show).

Considerando que a instituição em que se deu a pesquisa é uma escola que se propõe a ser experimental, parece urgente que se desenvolvam ações no sentido de definir uma posição sobre e, se for o caso, implementar o uso das tecnologias na educação. Nesse sentido, vale destacar o que afirma Kenski (2003, p. 54) sobre a relação entre o espaço da escola e a sua proposta de ensino:

A disposição e o uso de móveis e equipamentos nas salas e nos laboratórios definem a ação pedagógica. A imagem apresentada pelas bibliotecas e salas ambientes, os espaços e quadras de esportes, os pátios, os jardins e os centros de convivência comunicam visualmente a filosofia de trabalho da escola. O espaço é uma das linguagens mais poderosas para dizer do fazer da escola.

No caso, a ausência de um laboratório ou sala de computadores que viabilize o trabalho com as tecnologias mostra o vazio, o espaço do não-fazer configurado nas respostas dos professores. Apesar de a escola possuir computadores ligados em rede, eles não são em número suficiente nem estão disponíveis para uso em atividades com alunos ${ }^{8}$.

Segundo a autora, as questões estruturais estão diretamente relacionadas com o modelo de educação tecnológica que a escola pretende oferecer aos seus alunos. Essa definição, por sua vez, passa por questões como: Tipo de equipamento a ser adquirido? Quantidade? Condições de uso? Espaços? Apoios técnicos disponíveis? Manutenção e assistência técnica dos equipamentos? Ou seja, se a opção for pelo ensino com computador, segundo Kenski (2003), essa escolha interferirá em toda a lógica do ensino e da ação docente.

O segundo item mais assinalado para indicar os fatores que impedem ou dificultam o uso das tecnologias também está relacionado à infraestrutura, mais especificamente à

\footnotetext{
${ }^{8}$ Em 2007, foi instalado um Laboratório de Informática na escola em que se deu a pesquisa, com microcomputadores em número suficiente para grupos de 25 alunos.
} 
falta de pessoal para o apoio técnico ${ }^{9}: 15$ professores/as (46,87\% do total) assinalaram que não há profissionais na instituição para o apoio técnico necessário.

Buzato (2001, p. 230) alerta para o fato de que a formação letrada prévia "[...] não basta para a superação das barreiras iniciais ao domínio das novas maneiras de produzir e interpretar sentidos e dos novos recursos expressivos característicos do meio cibernético." Ao discutir "O Caso Teresa", o autor demonstra o quão fundamental é o "papel do par mais competente" como facilitador/mediador na aquisição do letramento eletrônico. ${ }^{10}$

O terceiro fator mais indicado como impedindo ou dificultando o uso das tecnologias na prática docente desloca a questão do âmbito da instituição para o âmbito dos saberes docentes: 11 professores/as (34,37\% do total) assinalaram o item não tenho o conhecimento necessário para utilizar esses recursos. Essa preocupação pode ser confirmada nas respostas de 12 professores/as que indicaram o conhecimento técnico para usar as tecnologias como característica necessária ao professor para a utilização das TIC na educação:

P5 - Domínio do uso das tecnologias

P9 - Conhecimento e necessidade.

P13 - Gostar dessas tecnologias e saber usá-las.

P15 - Conhecimento das tecnologias existentes e de suas utilizações, e acesso a elas.

P16 - Pelo menos ter conhecimentos básicos de informática.

P17 - Domínio da operação das máquinas.

P19 - Necessita primeiramente conhecer as tecnologias disponíveis e saber bem utilizá-las, para depois propor um trabalho pedagógico com os alunos.

P20 - Conhecimento, equipamento adequado e apoio técnico.

P21 - Conhecimento das mesmas.

P27 - É preciso ter domínio das TICs e desejar inseri-las no cotidiano da sala de aula.

P30 - Saber usar essas tecnologias.

P32 - Conhecer e utilizar adequadamente a seus objetivos.

Apesar de os/as professores/as que participaram da pesquisa terem um excelente nível de formação - aproximadamente $80 \%$ possuem Mestrado ou Doutorado, eles fizeram questão de enfatizar a carência do conhecimento técnico necessário para a utilização das tecnologias em sala de aula. Kenski (2003, p. 77) destaca que é importante "[...] que os professores se sintam confortáveis para utilizar esses novos auxiliares didáticos." Ou seja, eles precisam "[...] conhecê-los, dominar os principais procedimentos técnicos para

\footnotetext{
${ }^{9}$ A partir de 2008, a alternativa encontrada foi a colaboração de bolsistas para o desenvolvimento das atividades pedagógicas no Laboratório de Informática.

10 Buzato (2001, p. 230) esclarece que "Podemos nomear o tipo de conhecimento que permite ao indivíduo inserir-se nas práticas letradas da era digital como letramento digital, ciberletramento ou letramento eletrônico".
} 
sua utilização, avaliá-los criticamente e criar novas possibilidades pedagógicas, partindo da integração desses meios com o processo de ensino".

No que se refere à capacitação profissional para o uso das tecnologias, a autora toma como referência os dados do National Information Infrastructure Advisory Concil, conselho ligado ao governo americano, órgão colegiado que apresenta as habilidades e o tempo necessários para os docentes desenvolverem um trabalho satisfatório com as TICs na sala de aula.

Segundo o referido conselho, a etapa da adoção, que corresponde ao uso básico da tecnologia, necessita de 30 horas de capacitação. A etapa de adaptação, que prevê a descoberta de aplicações para o uso da tecnologia e conhecimento operacional para detectar falhas, precisa de mais 45 horas de treinamento ${ }^{11}$; três meses de experiência e apoio técnico. A fase da apropriação, que corresponde ao domínio sobre a tecnologia para alcançar os objetivos pedagógicos, necessita de mais 60 horas de treinamento; dois anos de experiência e apoio técnico permanente. A etapa da invenção, na qual o professor utiliza a tecnologia como ferramenta flexível, desenvolvendo novas habilidades de ensino, prevê mais 80 horas de treinamento; entre quatro e cinco anos de experiência; apoio técnico imediato (KENSKI, 2003).

O que se percebe é que a autora problematiza questões de fundo sem a ilusão de que as maravilhas das TICs provocarão mudanças imediatas na escola; há sérios obstáculos que precisam ser enfrentados e cujas soluções só serão viabilizadas a médio e longo prazo com uma política institucional específica para tal fim.

Considerou-se relevante apresentar a discussão desses dados da pergunta 6 nesse ponto da análise, uma vez que têm relação direta com o terceiro item assinalado pelos professores na pergunta 5 como dificultador para o uso das tecnologias na sua prática docente. A seguir, serão apresentados outros aspectos elencados pelo grupo participante de pesquisa, tomando por referência o estudo de Ramal (2002) ${ }^{12}$ sobre as características necessárias ao professor para utilizar as tecnologias com fins educacionais.

\subsection{Características necessárias ao professor/a}

Ramal (2002, p. 191-203) caracteriza o profissional que vai trabalhar com as novas tecnologias na educação como "arquiteto cognitivo" e desdobra o conceito em quatro aspectos que vão sendo agregados um ao outro. Dentre o conjunto de características apresentado pelos/as professores/as da escola em que se deu a pesquisa, em resposta à

\footnotetext{
11 Apesar de considerar o termo "formação” mais compatível com as discussões atuais sobre saberes docentes e formação de professores, mantivemos o termo “treinamento” adotado por Kenski na obra referenciada.

${ }^{12}$ Vale destacar que Ramal desenvolveu sua pesquisa com profissionais (docentes ou não) das áreas de informática, de educomunicação, de pedagogia e uma usuária comum das tecnologias. Tais profissionais atuam em escola da rede pública, na formação de professores, na elaboração de softwares educacionais. No grupo de participantes da presente pesquisa, todos os profissionais são da área da educação, nenhum tem formação específica na área de informática, todos atuam junto a crianças, adolescentes e jovens da educação básica (90\% em sala de aula).
} 
pergunta $6^{13}$, serão discutidas, na sequência aquelas que coincidem com os aspectos postulados pela referida autora, embora se saiba que essa categorização não contempla todo o conteúdo das respostas fornecidas.

$\left.1^{\circ}\right)$ "O arquiteto cognitivo é um profissional" - a autora afasta do perfil desse profissional a concepção de mestre por vocação ou dom natural e o caracteriza como um professor preocupado com a sua formação pedagógica. Algumas manifestações do grupo participante de pesquisa destacam a importância da atualização e da qualificação permanente:

P4 - Atualização permanente, inclusive quanto ao uso das novas tecnologias; disponibilidade de tempo para tal.

P6 - [...] atualização constante desse professor (autonomia profissional);

P3 - Ser um usuário; estar atualizado com relação ao q/ é produzido e difundido nessa área.

P14 - O professor deve atualizar-se e buscar conhecimentos na área para poder utilizar a tecnologia com segurança e facilidade.

P18 - Acho que o professor de modo geral tem que ter a facilidade de aceitar desafios, que neste caso seria o de qualificar e atualizar sobre as tecnologias educacionais mais recentes.

P23 - Ser instrumentalizado, atualizado.

$2^{\circ}$ ) "O arquiteto cognitivo é um profissional capaz de traçar estratégias e mapas de navegação que permitam ao aluno empreender, de forma autônoma e integrada, os próprios caminhos de construção do (hiper)conhecimento em rede." - As mudanças nas formas de construção do saber fazem pensar a necessidade de ressignificar as teorias pedagógicas, considerando o novo contexto da educação. O aluno vivencia um processo cultural no qual a sua relação com o conhecimento e com o mundo passa pela incorporação das tecnologias, o que pode desencadear novas formas de aprender. O grupo participante de pesquisa apontou como características necessárias ao profissional que vai trabalhar nesse novo contexto de ensino-aprendizagem:

P5 - [...] domínio do uso das tecnologias; criatividade na sua utilização; planejamento prévio das atividades.

P8 - Primeiro o professor deve conhecer, selecionar o que e com o que trabalhar... algo que complete os conhecimentos traçados pelo professor como necessários, dentro dos seus objetivos.

P10 - Ser bem informado e saber relacionar os temas com os recursos disponíveis; ter claro que a tecnologia são meios p/ estimular, ilustrar e possibilitar outro olhar p/ o que está sendo debatido.

P30 - Saber relacionar tecnologia com educação.

P32 - Conhecer e utilizar adequadamente a seus objetivos.

\footnotetext{
${ }^{13}$ Pergunta 6: Na sua opinião, que características são necessárias ao professor para a utilização das tecnologias com fins educacionais?
} 
$3^{\circ}$ ) "O arquiteto cognitivo é um profissional capaz de traçar estratégias e mapas de navegação que permitam ao aluno empreender, de forma autônoma e integrada, os próprios caminhos de construção do (hiper)conhecimento em rede; assumindo, para isso, uma postura consciente de reflexão-na-ação." - Considerando que a formação docente nem sempre capacita para as situações a serem vivenciadas no cotidiano escolar, o professor precisa ter a postura de um investigador atento e crítico, disposto a estar permanentemente repensando a sua prática. A importância de refletir sobre a prática e transformá-la em conhecimento aparece na fala dos/as professores/as pesquisados/as:

P1 - As características de um professor-pesquisador, curioso, interessado nas inovações pedagógicas-tecnológicas, porém crítico e flexível para aprender com os alunos e em interação com o grupo, quando não familiarizado com as novas tecnologias.

P11 - Abertura para aprender constantemente tanto sobre as tecnologias como sobre o uso que os alunos fazem dessas tecnologias.

P28 - Penso que o prof. necessita inicialmente ter o desejo da "aventura"; daí pra frente precisa estar aberto ao novo e ter espírito de pesquisador para encontrar as possibilidades pedagógicas adequadas.

$4^{\circ}$ ) "O arquiteto cognitivo é um profissional capaz de traçar estratégias e mapas de navegação que permitam ao aluno empreender, de forma autônoma e integrada, os próprios caminhos de construção do (hiper)conhecimento em rede; assumindo, para isso, uma postura consciente de reflexão-na-ação e fazendo um uso crítico das tecnologias como novos ambientes de aprendizagem." - É preciso ter clareza de que o uso da tecnologia é uma forma de mediação para os processos pedagógicos e que não pode implicar uma violação de valores ou ignorar questões éticas.

P2 - Discutir, fundamentalmente discutir com colegas os usos, limites e possibilidades do uso das tecnologias.

P26 - Capacidade para usar tais tecnologias como apoio/complemento, não permitindo que esta prática substitua a atividade do professor; saber dosar o seu uso.

P31 - Ter a percepção de que a tecnologia utilizada é um recurso a mais para suas aulas. É um meio que pode, tanto ajudar, quanto comprometer.

Como se pode observar, a fim de desenvolver as habilidades exigidas para a utilização das TICs na prática docente, o grupo participante de pesquisa apontou a necessidade de mobilizar saberes provenientes de várias fontes: saberes profissionais, disciplinares, curriculares e da experiência (TARDIF, 1991).

Além do conhecimento técnico, discutido na seção anterior (3.2), e das quatro características destacadas por Ramal (2002), os/as professores/as também relacionaram nas suas respostas os seguintes aspectos: interesse, criatividade, planejamento e acesso. 


\section{CONSIDERAÇÕES FINAIS}

Apesar de não ter sido possível analisar a totalidade das contribuições apresentadas nas respostas fornecidas pelo grupo participante de pesquisa, o recorte feito possibilitou reflexões valiosas para a compreensão do posicionamento desses profissionais frente ao desafio de incorporar à sua prática cotidiana na sala de aula as tecnologias de informação e comunicação.

No que se refere aos recursos tecnológicos mais utilizados, foi possível verificar que algumas tecnologias - adotando a definição do termo dada por Carneiro (2002) - têm seu uso consolidado na escola em que se realizou a pesquisa: o videocassete, o DVD, o aparelho para CD, o data show e o televisor são utilizados por $70 \%$ a $80 \%$ dos/as professores/as na sua prática docente. Já o computador é utilizado nas atividades com os alunos por pouco mais de $50 \%$ do grupo pesquisado, embora mais de $90 \%$ tenham declarado fazer uso de ambientes virtuais para atividades como comunicação pessoal, lazer...

Os maiores obstáculos para a utilização do computador com fins pedagógicos, de acordo com os motivos apresentados pelos/as professores/as, são o fato de a escola não dispor de laboratório nem de equipamentos em número suficiente para serem utilizados pelos alunos. Além disso, não há profissionais disponíveis para o apoio técnico necessário para que os docentes desenvolvam atividades didáticas mediadas pelo computador com os alunos.

Como defende Kenski (2003, p. 71), "[...] para que a escola possa estar conectada ao ambiente tecnológico das redes é preciso, antes de tudo, possuir a infra-estrutura adequada: computadores em número suficiente, de acordo com a demanda prevista para sua utilização; modems e formas diversificadas e velozes de conexão (via telefone, cabo, rádio...)."

Não se pode ignorar os equívocos que estão sendo cometidos, como equipar as escolas sem preparar os professores ou ter uma equipe qualificada sem a contrapartida institucional de infraestrutura e apoio técnico necessários. Por outro lado, autores como Kenski apontam caminhos para que esse desafio não paralise os profissionais da educação; ao contrário, segundo ela, importa que se possa fazer a exploração consciente dessas tecnologias como mais um recurso pedagógico.

No que se refere às características necessárias ao professor para utilizar as TICs, percebe-se que o grupo tem conhecimento da complexidade do desafio que está implicado nesse novo saber. As características elencadas apontam habilidades necessárias para utilização das tecnologias como mediadoras no processo de ensinoaprendizagem.

As resistências explicitadas na literatura em momentos anteriores parecem ter sido superadas; não se pode mais negar que essas tecnologias fazem parte hoje do conjunto de possibilidades de mediação das interações nas mais diversas esferas do convívio social - inclusive na esfera da escola! 
Admitir que se está vivendo uma época em que as novas tecnologias são constitutivas das práticas sociais de interação não significa acreditar ingenuamente que, "como num passe de mágica", o professor reinventará seu fazer pedagógico, incorporando as TICs no cotidiano da sala de aula.

Para fazer uso dessas tecnologias de informação e comunicação na sua prática docente, os/as professores/as apontaram a necessidade de conhecimentos que deveriam ser transmitidos/desenvolvidos na formação profissional inicial, nas faculdades de educação e programas de formação docente, responsáveis tanto pelo fornecimento do arcabouço ideológico dos saberes pedagógicos quanto de algumas técnicas e formas de saber-fazer (TARDIF, 1991).

Por outro lado, cabe à instituição escolar não só o fornecimento da infraestrutura necessária para o uso das TICs na prática docente (KENSKI, 2003), mas também a oferta de cursos de formação continuada que viabilizem o desenvolvimento dos programas escolares - que envolvem os saberes curriculares (objetivos, conteúdos e métodos) (TARDIF, 1991). Não obstante, o que se observa nas respostas fornecidas pelos/as professores/as é que nem os cursos de formação inicial, nem a formação continuada ofertada pela escola estão contemplando as habilidades necessárias para o uso das TICs no cotidiano dessa escola.

Esse novo conhecimento exigido na profissionalização docente nos leva a refletir sobre a necessidade de repensar tanto os cursos de formação inicial quanto os programas aligeirados de formação continuada, pois as habilidades necessárias para a utilização dessas tecnologias como mediadoras na prática pedagógica exigem tempo de capacitação/experiência e apoio técnico permanente, sem os quais essa reinvenção nas práticas do professor é uma ilusão. O comentário de P3 sobre a pesquisa parece sintetizar a problemática vivenciada pelo grupo participante de pesquisa:

[...] a utilização de tecnologias com fins educacionais pode se tornar um recurso muito significativo para a escola e para a educação, desde que a instituição disponha de tais recursos e apresente ao profissional meios e condições para que se atualize. Em geral há uma crença no autodidatismo como opção de conhecimento do professor. Caso contrário, tais recursos continuarão sendo admirados a distância.

Assim, entende-se que os aspectos discutidos no presente artigo constituem dados bastante relevantes para a elaboração de uma proposta de ação da escola, tanto no sentido de se adequar às necessidades estruturais quanto de formação dos seus profissionais. Compete, entretanto, à comunidade escolar dessa instituição (compreendendo todos os seus atores) decidir que formação quer proporcionar a seus alunos e que ações serão priorizadas para viabilizar o seu projeto político pedagógico.

Trahtemberg (2000, p. 15), ao discutir o impacto das novas tecnologias na escola, aponta alguns objetivos comuns que podem ser encarados de forma cooperativa na América Latina e no Caribe. Dentre os objetivos que se referem à capacitação de professores, vale destacar o seguinte: "Esta capacitación debe incluir no solo el nuevo uso de la computadora, el vídeo y la tecnologia, sino la nueva organización del tiempo y 
de los horários de clase, y aprender a discriminar entre la multiplicidad de materiales, equipos y software a su alcance.”.

O autor também enfatiza a importância de que os programas (software) educativos respondam a demandas locais e regionais, evitando a dependência dos países ricos, a má aplicação de recursos e a perda de tempo educando mal os alunos.

\section{REFERÊNCIAS}

BLIKSTEIN, Paulo; ZUFFO, Marcelo Knörich. As sereias do ensino eletrônico. In: SILVA, M. (Org.) Educação online. São Paulo: Edições Loyola, 2003. p. 23-38.

BRASIL. Secretaria de Educação Fundamental. Parâmetros Curriculares Nacionais: terceiro e quarto ciclos do ensino fundamental: introdução aos parâmetros curriculares nacionais. Brasília: MEC/SEF, 1998.

Ministério da Educação, Secretaria de Educação Média e tecnológica. Parâmetros Curriculares Nacionais: Ensino Médio. Brasília: Ministério da Educação, 1999.

BUZATO, Marcelo El Khouri. Sobre a necessidade de letramento eletrônico na formação de professores: O Caso Teresa. In: GRIMM-CABRAL, Loni, SOUZA, Pedro de, LOPES, Ruth E. Vasconcellos, PAGOTTO, Emílio Gozze (Orgs.). Lingüística e ensino: novas tecnologias. Blumenau: Nova Fronteira, 2001. p. 229-267.

CARNEIRO, Raquel. Informática na educação: representações sociais do cotidiano. 2. ed. São Paulo: Cortez, 2002.

KENSKI, Vani Moreira. Tecnologias e ensino presencial e a distância. Campinas, SP: Papirus, 2003.

LÉVY, Cibercultura. São Paulo: Editora 34, 2005.

MAGGIO, Mariana. O campo da tecnologia educacional: algumas propostas para sua reconceitualização. In: LITWIN, Edith (Org.). Tecnologia educacional. Porto Alegre: Artes Médicas, 1997. p. 12-22.

MASETTO, Marcos, T. Mediação pedagógica e o uso da tecnologia. In: MORAN, José Manuel; MASETTO, Marcos, T.; BEHRENS, Marilda Aparecida. Novas tecnologias e mediação pedagógica. 8. ed. Campinas, SP: Papirus, 2004. p. 133-173.

NISKIER, Arnaldo. Tecnologia educacional: uma visão política. Petrópolis, RJ: Vozes, 1993.

PINTO, Álvaro Vieira. O conceito de tecnologia. v. 1. Rio de Janeiro: Contraponto, 2005. 
PONTE, João Pedro da. Tecnologias de informação e comunicação na formação de professores: Que desafios? Revista Ibero-Americana de Educación. OEI. N. 24, septiembre/diciembre, 2000. Disponível em http://www.oei.es/revista.htm. Acesso em 23/11/06.

RAMAL, Andrea Cecília. Educação na cibercultura: hipertextualidade, leitura, escrita e aprendizagem. Porto Alegre: Artmed, 2002.

ROJO, Roxane; BARBOSA, Jacqueline Peixoto; COLLINS, Heloísa. Letramento digital: um trabalho a partir dos gêneros do discurso. In: KARWOSKI, Acir Mário; GAYDECZKA, Beatriz; BRITO, Karim Siebeneicher (Orgs.). Gêneros textuais: reflexões e ensino. Palmas e União da Vitória, PR: Kaygangue, 2005.

TAJRA, S. F. Informática na educação: professor na atualidade. São Paulo: Érica, 1998.

TARDIF, Maurice. Saberes docentes e formação profissional. Petrópolis, RJ: Vozes, 2002.

Os professores face ao saber docente: esboço de uma problemática do saber docente. Revista Teoria e Educação, Porto Alegre, n. 4, 1991. p. 215-233.

TRAHTEMBERG, Leon. El impacto previsible de lãs nuevas tecnologias em la enseñanza y la organización escolar. Revista Ibero-Americana de Educación. OEI. N. 24, septiembre/diciembre, 2000. Disponível em http://www.oei.es/revista.htm. Acesso em 23/11/06. 


\title{
A N E X O I - INSTRUMENTO DE PESQUISA SOBRE EDUCAÇÃO E USO DAS TECNOLOGIAS DA INFORMAÇÃO E DA COMUNICAÇÃO
}

\author{
Prezado(a) Colega:
}

Para atender às exigências do PPGL/UFSC, um dos requisitos é a qualificação de dois artigos em áreas diferentes da área na qual o projeto de tese está inserido. A Educação foi uma das áreas que escolhi e pretendo produzir um dos artigos tendo por base dados coletados nesta escola sobre o uso das tecnologias da informação e da comunicação na educação. Nesse sentido, conto com a sua colaboração quanto ao fornecimento dos dados solicitados a seguir.

$1^{\text {a }}$ Parte - IDENTIFICAÇÃO

1. Sexo: ( ) feminino ( ) masculino

2. Disciplina que ministra ou área:

3. Formação:

Graduação em

Especialização em

Ano de conclusão:

Mestrado em Ano de conclusão

Doutorado em Ano de conclusão:

4. Situação funcional: ( ) Professor(a) Efetivo(a) Ano de conclusão:

5. Ano de ingresso no Colégio de Aplicação:

( ) Professor(a) Substituto(a)

2a Parte - TECNOLOGIAS DA COMUNICAÇÃO E INFORMAÇÃO

1. Que recursos tecnológicos você tem conhecimento de que a escola dispõe:
( ) gravador
( ) filmadora
( ) televisor
( ) rádio
( ) videocassete
( ) aparelho para CD
( ) computador em rede ( ) data show

2. Que recursos tecnológicos você utiliza em suas aulas:
( ) gravador
( ) filmadora
( ) rádio
( ) videocassete
( ) televisor
( ) computador em rede
( ) DVD
( ) aparelho para CD

3. Você utiliza ambientes virtuais para atividades como comunicação pessoal, atualização, formação, lazer? ( ) Sim - Quais?
( ) Rede (ambiente de buscas)
( ) e-mail
( ) ambiente chat síncrono

( ) foros de discussão assíncronos (lista de discussão) ( ) blogs ( ) videoconferências

(

outros:

\begin{tabular}{llllll}
\hline( & Não & utilizo & - & Motivo(s)
\end{tabular}

4. Você utiliza ambientes virtuais para atividades educacionais envolvendo os alunos?
( ) Sim - Quais?
( ) Rede (ambiente de buscas) ( ) e-mail ( ) ambiente chat síncrono
( ) foros de discussão assíncronos (lista de discussão) ( ) blogs ( ) videoconferências
( ) outros:
( ) Não utilizo - Motivo(s): 
5. Que fatores impedem ou dificultam o uso das tecnologias na sua prática docente?

( ) não disponho de equipamento adequado em casa

( ) não disponho de equipamento adequado em meu local de trabalho

( ) não tenho o conhecimento necessário para utilizar esses recursos

( ) não vejo necessidade de utilizar esses recursos na minha disciplina

( ) a instituição não incentiva o uso desses recursos

( ) não há profissionais na instituição para o apoio técnico necessário

( ) meus alunos não têm as condições socioeconômicas necessárias

( ) o computador está associado à sociedade de consumo e à globalização

( ) o ambiente virtual é incompatível com as características do ambiente escolar

( ) não conheço bons materiais educativos construídos com recursos multimídia

( ) outros:

6. Na sua opinião, que características são necessárias ao professor para a utilização das tecnologias com fins educacionais?

7. $\quad$ Cite alguns aspectos positivos da utilização das tecnologias na educação.

8. Cite alguns aspectos negativos da utilização das tecnologias na educação.

9. Você utiliza algum material educativo multimídia que considera adequado aos seus objetivos pedagógicos? Qual? Quais?

10. Relacione sites que costuma consultar ou indicar para seus alunos.

Comentário livre sobre o assunto da pesquisa.

Agradeço sua valiosa contribuição e solicito a devolução deste, em meu escaninho, até 10/02/06. 


\section{A N E X O I I - RESPOSTAS INSTRUMENTO DE PESQUISA SOBRE EDUCAÇÃO E USO DAS TECNOLOGIAS DA INFORMAÇÃO E DA COMUNICAÇÃO}

QUESTÃO 6 - Na sua opinião, que características são necessárias ao professor para a utilização das tecnologias com fins educacionais?

P1 - As características de um professor-pesquisador, curioso, interessado nas inovações pedagógicastecnológicas, porém crítico e flexível para aprender com os alunos e em interação com o grupo, qdo não familiarizado com as novas tecnologias.

P2 - Discutir, fundamentalmente discutir com colegas os usos, limites e possibilidades do uso das tecnologias.

P3 - Ser um usuário; estar atualizado com relação ao q/ é produzido e difundido nessa área, ter acesso aos meios, nem sempre disponíveis.

P4 - Atualização permanente, inclusive quanto ao uso das novas tecnologias; disponibilidade de tempo para tal; iniciativa e desejo de querer usar as novas tecnologias com fins educacionais.

P5 - domínio do uso das tecnologias; criatividade na sua utilização; planejamento prévio das atividades.

P6 - atualização constante desse professor (autonomia profissional); misto de criatividade $e$ planejamento dos conteúdos escolares; clareza de que tais" recursos" tecnológicos são "RECURSOS" apenas.

P7 - Ter vontade de aprendê-las, ter como usá-las na escola. Falta incentivo!

P8 - Primeiro o professor deve conhecer, selecionar o que e com o que trabalhar... algo que complete os conhecimentos traçados pelo professor como necessários, dentro dos seus objetivos.

P9 - Conhecimento e necessidade.

P10 - Ser bem informado e saber relacionar os temas com os recursos disponíveis; ter claro que a tecnologia são meios $p /$ estimular, ilustrar e possibilitar outro olhar p/ o que está sendo debatido.

P11 - Abertura para aprender constantemente tanto sobre as tecnologias como sobre o uso que os alunos fazem dessas tecnologias.

P12 - Atualização e interesse.

P13 - Gostar dessas tecnologias e saber usá-las.

P14 - O professor deve atualizar-se e buscar conhecimentos na área para poder utilizar a tecnologia com segurança e facilidade.

P15 - Conhecimento das tecnologias existentes e de suas utilizações, e acesso a elas.

P16 - Pelo menos ter conhecimentos básicos de informática.

P17 - Domínio da operação das máquinas.

P18 - Acho que o professor de modo geral tem que ter a facilidade de aceitar desafios, que neste caso seria o de qualificar e atualizar sobre as tecnologias educacionais mais recentes. Neste sentido, acho que um projeto de pesquisa poderia atender esta demanda e ao mesmo tempo, avaliar a procura e o interesse dos profissionais da escola.

P19 - Necessita primeiramente conhecer as tecnologias disponíveis e saber bem utilizá-las, para depois propor um trabalho pedagógico com os alunos.

P20 - Conhecimento, equipamento adequado e apoio técnico.

P21 - Conhecimento das mesmas.

P22 - Ter interesse e vontade de buscar atualização profissional.

P23 - Ser criativo. Ser instrumentalizado, atualizado.

P24 - Boa vontade.

P25 - Acesso ao material pedagógico e aos recursos tecnológicos, curiosidade e desejo em realizar novas experiências educacionais.

P26 - Capacidade para usar tais tecnologias como apoio/complemento, não permitindo que esta prática substitua a atividade do professor; saber dosar o seu uso.

P27 - É preciso ter domínio das TICs e desejar inseri-las no cotidiano da sala de aula.

P28 - Penso que o prof. necessita inicialmente ter o desejo da "aventura"; daí pra frente precisa estar aberto ao novo e ter espírito de pesquisador para encontrar as possibilidades pedagógicas adequadas.

P29 - Interesse.

P30 - Saber usar essas tecnologias. Saber relacionar tecnologia com educação.

P31 - Ter a percepção de que a tecnologia utilizada é um recurso a mais para suas aulas. É um meio que pode, tanto ajudar, quanto comprometer.

P32 - Conhecer e utilizar adequadamente a seus objetivos 